\title{
Analysis of Information Construction for Business Files of University Teachers
}

\author{
Zhao Lianfeng \\ Information Engineering Institute of Huzhou Teachers College \\ huzhou,china, 313000 \\ Email:zlf@hutc.zj.cn
}

\begin{abstract}
- as the actual reflection of the teaching and research ability of university teachers, teachers' business file has an important preservation and application value. The paper puts forward corresponding specific measures to implement information management and initially explores the ways to achieve these results from the composition, function, and significance of teachers' business files, as well as the necessity and requirement of business files construction.
\end{abstract}

KeyWords-university teachers; business files; informatization

Teachers' business files can be regarded as a collection of all kinds of materials in teaching and research with higher preservation value. It is an important part of university teachers' personnel files from the viewpoint of archival science study and application. It is not only an actual record for teaching and research, but also a real reflection for scientific research. Moreover, it provides a scientific reference basis for immediate control of teaching dynamic, teaching reform, teaching assessment, exploration of the law of higher education development and implementation of personnel training. With the rapid development of information and digital technology, the construction and management for the archive should not be limited to simple collection of paper materials and lists of files and contents. It makes use of systematic management concept and modern management tools to ensure rapid information storage and delivery. Meanwhile, it guarantees the information maintenance, immediacy and accuracy, so as to make the archive more important in universities management.

\section{COMPONENT ELEMENTS OF TEACHERS’ BUSINESS} FILES

The teachers' business files is mainly transformed by many materials, such as teachers' basic information, published papers in the process of teaching and research, research projects and various awards. Based on the author's work practice, the paper briefly analyzes the basic parts of teachers' business files.

1. Teachers' basic information: teacher's name, gender, date of birth, nationality, native place, politics status, graduate school, graduate time, major, highest education, highest diploma, the time of attending job, professional research direction, professional and technical qualification, and promotion time, attending academic organizations and social post as well as information about individual study, work experience and personal details and others. The teachers' information and development can be directly and fully grasped from the basic information.

2. Basic teaching information: courses teachers give each semester, syllabus, teaching plan, teaching summary, class, the number of students, teaching workload, and mid-term and final evaluation of teaching performance, etc. It reflects teaching situation, attitude and performance of teachers each term in detail.

3. Awards of teaching achievements: research projects of teaching reform, social science journals, papers on teaching reform in magazines and newspapers, published academic monographs, textbooks and all kinds of awards of teaching achievement, etc. It makes objective measures about teachers' teaching and research abilities.

4. Awards of scientific achievements: national, provincial and municipal funded natural science subjects, science and technology projects, research projects, research papers, patent and various papers, awards of scientific achievements. It really reflects the teachers' level of scientific research.

5. Student Guidance: guiding students to submit for projects in the process of the teaching (such as student research projects, laboratory-based open project, etc.), papers published, patent application, SYB design competition, contest and skill training, etc. It reflects well on the teachers' scientific research abilities.

6. Education situation: in addition to their own teaching, scientific research, the university teachers have responsibilities to educate others including help and guide young teachers, postgraduate training, guidance of graduation design, practice guidance, thinking to guide, class teacher work and related honors. It reflects well on the university teachers' educational work.

7. Local service: with the increase of the research power in universities, teachers also need a platform to practice, so the relations between universities and enterprises gradually increase and bring many cooperation projects including enterprise authorized project, united application of universities and enterprises, and joint development of key technology, etc. It not only improves the teachers' practical ability but also makes contributions for local economic construction. 


\section{THE IMPORTANCE OF THE CONSTRUCTION FOR TEACHERS' BUSINESS FILES}

A teacher is the main practitioner and pusher to teaching and scientific research. Therefore, strengthening of the construction for teachers' business files is not only the need of archival center but also the need of school development and expansion and extension of teachers' personnel files. The teachers' business files can comprehensively and dynamically reflects the teachers' teaching, research and examinations. Moreover, it is an important reference for teaching reform and scientific management. Therefore, the teachers' business files have strong practical significance and historical value.

1. The teachers' business file is the development direction of school's adjustment and an important reference for scientific management. As a whole, it reflects the teachers' comprehensive quality and academic levels and provides an important reference for running schools, clear direction and goal for development. It also gives a direction to explore and reveal the school's features and professional advantages and to adapt to the requirements of social development. Meanwhile, in order to improve the level of scientific management, it provides a reference basis to establish practical reform and construction plans, and establish and improve the rules and regulations.

2. The teachers' business file is an important foundation to improve the work of teaching and research. The archive plays a material supporting role in teaching reform, scientific research project, professional declaration, inspection and other special work. It also provides teachers with many valuable references. They can find the past causes of the failure of their own and others and learn from the successful experience through the files so as to effectively encourage them to carry out the reform of teaching model, inspire young teachers to develop research activities and guarantee the continuous improvement for the quality of teaching and research.

3. The teachers' business file is an important basis to measure the overall quality of teachers. It can not only evaluate teachers' abilities but also evaluate the strength of teachers. Therefore, the collection, organization, statistics and analysis of the files should be done carefully and common information can be found to fully and objectively analyze the problems of the building of teachers. Moreover, it plays a very important role in special rectification work.

4. The teachers' business file is an important evidence for teachers' professional titles and promotion. It can objectively reflect professional knowledge and scientific research level. It is a basis for professional titles and promotion. For the teachers who apply for the professional and technical post, the archive can help them fill in the application form and provide a large amount of supporting materials as important proofs of teaching performance. Meanwhile, evaluating technical or professional title should be given a fair competition platform.

\section{INEVITABLE TENDENCY TO REFORM TRADITIONAL} TEACHERS' BUSINESS FILES
In recent years, with the frequent application of the teachers' business files and rapid development of computer and network information technology, university teachers have required more and more to establish information construction for the teachers' business files. The traditional files are stored in the form of paper materials and simply listed in a period of time, so there are a lot of defects in them. First, the files take up larger space. It's too slow to look up them, and it's not convenient to update the information. It spends many manpower, material and time to add and change the files when new teachers' information changes every year. The major problem is that the files can not obtain timely statistics for existing information and the data can not receive timely updating. Second, it makes teachers in each department not familiar with the research and teaching status. Sometimes they fail to find the necessary information (including collection and adjustment of supporting materials) they need in time when they want to apply for projects, which seriously affect their working efficiency. Third, the files seriously affect teachers' enthusiasm and passion in the establishment of the archive. In the face of relatively heavy teaching work, scientific research and pressure of study, the teachers have no time to fill in the registration form and renew their information, not to mention to provide material collection and adjustment. To this point, I feel that it's not convenient and useful in my previous work.

However, using computer can realize the network management of teachers' business files and overcome the above disadvantages. First, it can reduce the storage space of data to a large extent, save dispersed information resources in the form of digital, transmit and utilize through Internet, and carry on the fast inquiry and timely statistics of the data information. Meanwhile, it also strengthens the communication and sense of competition between teachers and students in the same college and improves work efficiency to a certain extent. Second, the computer and network technique has been widely used in management of colleges and universities, and with the gradual network of teaching management system and establishment of research management system and library management system, information construction of the teachers' business files has sufficient technical support and perfect network environment. The gradual application of paperless office OA system makes computer as a simple assistant tool become an indispensable work environment. Third, teachers support the construction from the heart and they have actual requirement for it. The present construction and management mode is unable to meet the actual work and requirements, so it is urgent to carry out information construction to fully arouse our enthusiasm and meet the needs of practical application.

\section{BASIC REQUIREMENTS FOR INFORMATION}

CONSTRUCTION OF THE TEACHERS’ BUSINESS FILES

\section{A Clear about Principles and Implement \\ Responsibilities}

Strengthening teachers' information construction for the teachers' business files should be strictly in accordance with basic principles of national archives administration. A unified organization, scientific classification and centralized 
management can ensure the successful implementation of information construction. First, universities must guarantee the information construction from three aspects: the first is about system guarantee. It is required to build the leadership, establish and improve files management, set up advance awareness and implement the specific post responsibilities; the second is about personnel guarantee. It should ensure that management post has professional staff and technical post equips with technical personnel. Responsibilities should be cleared about and corresponding performance evaluation mechanism should be established; the third is about equipment support. It fully guarantees the needs of computer equipment, system management software and data storage equipment in the process of information construction.

\section{B Strengthen the Construction of Information \\ Resources}

The core of information construction for teachers' business files is to enhance the construction of information resources. First, it is required to establish a unified data resource list according to the requirements of the construction, and clear about scopes and requirements of information collection; second, it is required to do well in publicity work. Because the file information source is from individual teachers, it needs to strengthen connection and communication with the teachers when collecting information, and to seek to understand and cooperate from the teachers. Third, teachers also need timely communication with file managing staff, and update their information such as research projects, published papers, awards, etc., and provide related paper materials to ensure the electronic information match with the paper materials.

C Strengthen the Construction of Information System

First, according to classification and design standards of the national archives administration and data analysis and design requirements based on actual application, the file management system for teachers' business files will be developed and suitable to the network environment. The information and network construction should be strengthened to ensure the quality of the information resources and data sharing and exchange through the Internet. Second, we should gradually improve network level for archives, improve service and management levels, and give each teacher a separate user account and password to allow them to inquire, output, and print their archives through the Internet. Meanwhile, the system can manage itself and update information, which greatly improve the efficiency of archives management.

\section{REFERENCES}

[1] Wang Xiaohui, Ji Hua, Zheng, Mingxue, Analysis on Information Management of Teaching Business Files for University Teachers [J], Higher Education of Sciences. 2008 (4)

[2] Deng Xiaobing, Thinking on Accelerating Infomatization Construction of Achieves [J], Lantai World. 2008 (06)

[3] Zhang Feng, Lu Jiawei, Exploration and Practice for Networking Management of Business Files of University Teachers [J], Modern Economy (Modern Property, later -half month magazine). 2009 (3)

[4] Liu Lixian, Collection, Management and Application of Business Files of University Teachers [J], Journal of Hunan University of Science and Engineering. 2009 (01)

[5] Jin Yulan, Analysis on Management and Development of Business Files for University Teachers [J], Lantai World. 2010 (12)

[6] Wang Guangjuan, On Development and Utilization of Archieve Information resources of University [J], Shanxi Science and Technology. 2011 (1)

[7] Liu Dongmei, On Management and Reform of Business Files for University Teachers [J], Journal of Hunan University of Technology (Social Science Edition). 2011 (4) 